\title{
Características de carcaça e carne de cordeiros mestiços de três grupos genéticos
}

\section{Carcass and meat characteristics of crossbred lambs from three genetic groups}

\author{
Edson Luis de Azambuja Ribeiro ${ }^{1 *}$; Humberto Cardoso Oliveira ${ }^{2}$; \\ Filipe Alexandre Boscaro de Castro ${ }^{2}$; Ivone Yurika Mizubuti ${ }^{1}$; \\ Leandro das Dores Ferreira da Silva ${ }^{3}$; Marco Aurélio Alves de Freitas Barbosa ${ }^{3}$
}

\section{Resumo}

\begin{abstract}
Este trabalho teve como objetivo avaliar as características de carcaça e a qualidade de carne de cordeiros dos grupos genéticos $1 / 2$ Texel - 1/2Hampshire Down (THD), 1/2 Texel - 1/2Ile de France (TIF) e 1/2Texel - 1/2Suffolk (TS). Foram utilizados 17 cordeiros castrados, sendo seis THD, seis TIF e cinco TS, confinados por 51 dias. Os animais receberam, diariamente, ração concentrada comercial (18\% PB e $74 \%$ NDT) na proporção de $1,5 \%$ do peso vivo, mais cana-de-açúcar picada in natura à vontade. No início do experimento os cordeiros tinham idade e peso médio inicial de 120 dias e $31,0 \mathrm{~kg}$. No final do período experimental os cordeiros foram abatidos após jejum de sólidos de 16 horas. Não houve diferenças significativas $(\mathrm{P}>0,05)$ para peso e rendimento de carcaça fria. As médias gerais foram $17,30 \mathrm{~kg}$ e $41,94 \%$, respectivamente. A composição regional (pescoço, paleta, costelas e pernil) e as características morfológicas (comprimento e compacidade) das carcaças também não diferiram ( $\mathrm{P}>$ 0,05 ) entre os grupos genéticos. A composição tecidual do pescoço e a qualidade da carne (maciez, suculência e sabor), avaliada por um painel sensorial, também, foram similares $(\mathrm{P}>0,05)$ entre os três grupamentos genéticos. Conclui-se que na produção de carne ovina qualquer um dos grupos genéticos estudados pode ser utilizado, pois apresentam características de carcaça e de carne semelhantes.

Palavras-chave: Características morfológicas, composição regional, composição tecidual, cruzamento, maciez, ovinos.
\end{abstract}

\footnotetext{
Abstract

The objective of this work was to evaluate carcass characteristics and meat quality of lambs from the genetic groups 1/2Texel - 1/2Hampshire Down (THD), 1/2Texel - 1/2Ile de France (TIF) and 1/2Texel $1 / 2$ Suffolk (TS). Seventeen castrated lambs were used, being six THD, six TIF and five TS. Lambs were fed lot for 51 days, where they received daily a commercial concentrate ration ( $18 \% \mathrm{CP}$ and $74 \% \mathrm{TDN})$, in the proportion of $1.5 \%$ of body weight, and had free access to chopped in natura sugar cane. The average age and weight at the initiation of the experiment were, respectively, 120 days and $31.0 \mathrm{~kg}$. At the end of the experimental period lambs were slaughtered after 16 hours of fasting of solids. There was no significant difference $(\mathrm{P}>0.05)$ for cold carcass weight and dressing percentage. Averages were $17.30 \mathrm{~kg}$ and $41.94 \%$, respectively. Regional composition (neck, shoulder, ribs and leg) and carcass

${ }^{1}$ Profs. Drs.Universidade Estadual de Londrina - UEL, Centro de Ciências Agrárias - CCA, Departamento de Zootecnia. CEP 86051-970, Londrina, Pr. Bolsista de produtividade do CNPq.E-mail: elar@uel.br; mizubuti@uel.br

2 Programa de Pós-Graduação em Ciência Animal da Universidade Estadual de Londrina-UEL. Londrina, Pr. E-mail: humbertoco@, uol.com.br; fabcastro76@yahoo.com.br

${ }^{3}$ Profs. Drs. Universidade Estadual de Londrina - UEL, Centro de Ciências Agrárias -CCA, Departamento de Zootecnia. Londrina, PR.E-mail: leandro@uel.br; maafbarbosa@uel.br

* Autor para correspondência
} 
morphological characteristics (length and compactness) did not differed $(\mathrm{P}>0.05)$ among the genetic groups. Tissue composition of the neck and meat quality (tenderness, juiciness and flavor), evaluated by a sensory panel, were similar $(\mathrm{P}>0.05)$ among the three genetic groups. It can be concluded that in the lamb production any of the genetic groups studied can be used, for their carcass and meat characteristics were quite similar.

Key words: Crossbreeding, morphological characteristics, regional composition, sheep, tissue composition, tenderness.

\section{Introdução}

Segundo Brisola e Santo (2003), apesar do brasileiro não ter o hábito de consumir carne ovina regularmente, o consumo tem aumentado. Este aumento está fazendo com que a ovinocultura se volte, principalmente, para produção de carne. Os autores citaram, ainda, que há necessidade de se oferecer carnes com qualidade e com regularidade. Estes fatores são importantes para manter os mercados já conquistados e conquistar novos consumidores.

O mercado consumidor está cada vez mais exigente, sendo necessário buscar alternativas para ampliar e diminuir a sazonalidade de oferta, com carnes com boa qualidade, padronizadas e certificadas. A carne de cordeiro viabiliza a ovinocultura, impulsionando o setor a incrementar sua eficiência produtiva. A produção de carne de cordeiro deve utilizar tecnologia adequada, aproveitando o potencial de crescimento dos ovinos jovens, utilizando-se animais com potencial para ganho de peso e uma alimentação adequada (SIQUEIRA, 1996).

Uma das maneiras de melhorar o desempenho produtivo e a qualidade da carne produzida é a utilização de raças e sistemas de cruzamento apropriados. As raças tipo carne ou seus cruzamentos, geralmente apresentam ganho de peso e características de carcaça e carne superiores às das raças de duplo propósito ou raças laneiras (KEMPSTER et al., 1987; CARDELLINO, 1989; SIQUEIRA, 1990; GARCIA; PEREIRA, 2003). Siqueira (1990) cita as raças Ile de France, Hampshire Down, Suffolk e Texel como as principais raças de corte criadas no Brasil.
Este trabalho teve como objetivo avaliar as características de carcaça e a qualidade de carne de cordeiros dos grupos genéticos Texel $\mathrm{x}$ Hampshire Down (THD), Texel x Ile de France (TIF) e Texel x Suffolk (TS).

\section{Material e Métodos}

O experimento foi conduzido no Sítio da Escolinha, localizado no município de Jandaia do Sul, Paraná, com latitude $23^{\circ} 36^{\prime} 10^{\prime \prime} \mathrm{S}$ e longitude $51^{\circ} 38^{\prime}$ 34" W. O município possui temperatura ambiental média anual de $17,4^{\circ} \mathrm{C}$, precipitação média anual de $1.439,8 \mathrm{~mm}$, sendo máxima em janeiro $(201,4$ $\mathrm{mm}$ em média) e mínima em junho $(56,5 \mathrm{~mm} \mathrm{em}$ média). As análises químicas foram realizadas no Laboratório de Nutrição Animal do Departamento de Zootecnia da Universidade Estadual de Londrina, Londrina, Paraná. O experimento foi conduzido de agosto a outubro de 2007.

Foram utilizados 17 cordeiros castrados, com idade aproximada de 120 dias, divididos em três grupos, sendo seis $1 / 2$ Texel - 1/2Hampshire Down, seis $1 / 2$ Texel $-1 / 2$ Ile de France e cinco 1/2Texel $1 / 2$ Suffolk. No confinamento, que foi realizado em aprisco coberto e, com piso ripado e elevado do solo. Os animais foram separados por grupos genéticos em baias coletivas. Os cordeiros foram vermifugados com produto a base de oxfebendazole na dosagem de 4,5 mg/kg de peso vivo no início do experimento.

As rações utilizadas eram isoprotéicas e isoenergéticas. Os ovinos receberam cana-de-açúcar (Saccharum spp L.) picada in natura (3,5\% PB e $63,0 \%$ NDT), e ração comercial específica para 
ovinos (Romagnoli ${ }^{\circledR}, 18 \%$ PB e $74 \%$ de NDT). O concentrado foi fornecido na proporção de $1,5 \%$ do peso vivo, e a cana-de-açúcar à vontade, permitindo sobra aproximada de $10 \%$ da ração total. Os cordeiros tinham acesso à água e sal mineralizado à vontade. $\mathrm{O}$ alimento foi fornecido uma vez ao dia às 14 horas. $\mathrm{O}$ ajuste do concentrado era feito semanalmente, sempre que era feito a pesagem dos animais.

Os animais tiveram um período de adaptação de 20 dias às condições experimentais. $\mathrm{O}$ período experimental teve duração de 51 dias. Os animais foram pesados antes do abate, que foi precedido por jejum de sólidos de 16 horas. A carcaça foi pesada logo após o abate e depois de refrigerada por 24 horas em câmara fria $\left(4^{\circ} \mathrm{C}\right)$.

$\mathrm{Na}$ carcaça fria foram tomadas várias medidas de acordo com Osório et al. (1998) e Osório e Osório (2005): comprimento de carcaça (distância entre a borda anterior da sínfise ísquio-pubiana e o bordo anterior da primeira costela em seu ponto médio), profundidade de tórax ou peito (distância reta máxima entre o dorso e o osso esterno), comprimento de pernil ou perna (distância mais curta entre a borda anterior da sínfise ísquio-pubiana e a porção média dos ossos do tarso), largura de pernil (distância entre as bordas interna e externa da parte superior do pernil), profundidade de pernil (maior distância reta entre a borda proximal e distal do pernil), comprimento de braço (distância entre o olécrano e a porção média dos ossos do carpo), perímetro de braço (tomada na porção média do comprimento do braço).

A compacidade da carcaça foi calculada pela divisão entre peso da carcaça fria e o comprimento de carcaça, e a compacidade de pernil pela divisão entre peso e comprimento de pernil. A espessura da gordura de cobertura foi medida sobre o músculo Longissimus dorsi entre a $12^{\mathrm{a}}$ e $13^{\mathrm{a}}$ costelas (OSÓRIO; OSÓRIO, 2005).

Após serem tomadas as medidas nas carcaças inteiras, as mesmas foram divididas longitudinalmente ao meio, sendo a metade esquerda separada nas seguintes regiões anatômicas: pescoço (porção compreendida entre a secção atlantoocipital e um corte oblíquo que passa entre a sétima vértebra cervical e a primeira dorsal), paleta (membro anterior da carcaça; na parte distal a secção é feita na porção média dos ossos do carpo), costela (parte da carcaça seccionada entre a última vértebra cervical e a primeira torácica e a última lombar e a primeira sacra) e pernil (membro posterior da carcaça, seccionado ao nível da articulação da última vértebra lombar e a primeira sacra e ao nível da porção média dos ossos do tarso) (OSÓRIO; OSÓRIO, 2005).

Opescoçofoicongeladoeutilizadoposteriormente para verificação da composição tecidual (músculo, osso e gordura). A dissecação foi realizada após descongelamento prévio em geladeira $\left(6^{\circ} \mathrm{C}\right)$ por 24 horas. Optou-se pela utilização do pescoço por ser de fácil obtenção e manuseio, pelo menor valor econômico, mas principalmente pelas altas correlações que a sua composição apresenta com a composição total da carcaça (PIOLA JÚNIOR, 2007).

Uma secção do músculo Longissimus dorsi foi retirada e congelada para análises posteriores (MULLER, 1980; BRIDI; SILVA, 2007). Para as análises, o músculo congelado foi cortado em fatias com 1,5 cm, e posteriormente descongelado em geladeira $\left(6^{\circ} \mathrm{C}\right)$ por 24 horas. As fatias foram pesadas congeladas e após o descongelamento para se obter as perdas por descongelamento. Parte das amostras foi usada para a determinação da composição centesimal e outra para a avaliação por um painel sensorial composto por cinco pessoas treinadas.

As amostras destinadas ao painel foram assadas em uma chapa elétrica a temperatura interna de $75^{\circ} \mathrm{C}$, deixando-se cinco minutos de cada lado. Para as avaliações de maciez, suculência e sabor foi utilizado uma escala de valores de 1 a 9 , onde 1 correspondia a uma carne extremamente dura, sem suculência e sem sabor; 5 é o valor médio; e 9 uma carne extremamente macia, suculenta e saborosa 
(MULLER, 1980). Pela diferença de peso das amostras antes e após assar foi determinada a perda pela cocção.

As análises de composição centesimal foram feitas de acordo com metodologias citadas por Silva e Queiroz (2002).

Os dados obtidos foram submetidos à análise de variância, onde a única fonte de variação foi o grupo genético. As diferenças entre médias foram comparadas pelo teste de Tukey ao nível de 5\% de probabilidade. As análises estatísticas foram realizadas no pacote estatístico SAS (1994).

\section{Resultados e Discussão}

Não houve diferenças $(\mathrm{P}>0,05)$ para os pesos e percentagens de carcaça e dos cortes, bem como para perdas no resfriamento, entre os três grupos genéticos (Tabela 1). O maior peso de carcaça para uma dada idade e, principalmente, dos cortes mais valorizados como o pernil são importantes, pois além de propiciar maior renda ao produtor, disponibilizam para o mercado carnes com melhor qualidade.

Tabela 1. Pesos e rendimentos da carcaça fria e dos cortes na meia-carcaça de cordeiros de três grupos genéticos.

\begin{tabular}{lccccc}
\hline \multirow{2}{*}{ Variáveis } & \multicolumn{3}{c}{ Grupos genéticos $^{1}$} & \multirow{2}{*}{ CV (\%) } & \multirow{2}{*}{ Prob. > F } \\
\cline { 2 - 3 } & T x HD & T x IF & T x S & & \\
\hline Carcaça Fria, kg & 17,17 & 16,93 & 17,74 & 11,13 & 0,7821 \\
Carcaça Fria, \% & 42,17 & 41,89 & 41,76 & 4,80 & 0,9431 \\
Perda Resfriamento, \% & 4,77 & 3,81 & 2,89 & 30,18 & 0,1722 \\
Meia Carcaça, kg & 8,63 & 8,45 & 8,86 & 11,14 & 0,7839 \\
Pescoço, kg & 0,53 & 0,63 & 0,56 & 24,47 & 0,4681 \\
Paleta, kg & 1,90 & 1,66 & 1,94 & 17,09 & 0,2867 \\
Costilhar, kg & 3,13 & 3,08 & 3,20 & 16,27 & 0,9314 \\
Pernil, kg & 3,07 & 3,08 & 3,16 & 10,19 & 0,8689 \\
Pescoço, \% & 6,20 & 7,45 & 6,30 & 20,54 & 0,2568 \\
Paleta, \% & 22,09 & 19,61 & 21,76 & 12,01 & 0,2254 \\
Costela, \% & 36,21 & 36,23 & 36,06 & 8,42 & 0,9951 \\
Pernil, \% & 35,49 & 36,70 & 35,87 & 8,84 & 0,8002 \\
\hline
\end{tabular}

${ }^{1} \mathrm{~T}$ x HD = 1/2Texel $-1 / 2$ Hampshire Down; T x IF = 1/2Texel $-1 / 2$ Ile de France; T x S = 1/2 Texel $-1 / 2$ Suffolk.

As similaridades observadas demonstram que os cordeiros cruzados Texel com as raças Hampshire Down, Ile de France e Suffolk apresentaram desempenho semelhante para estas características, possivelmente explicado por serem geneticamente próximos. Estes resultados concordam com Kempster et al. (1987) que não observaram diferenças para pesos de carcaça entre cordeiros filhos de carneiros Hampshire Down, Ile de France, Suffolk e Texel acasalados com ovelhas de três raças maternas. Ribeiro et al. (2001), também, observaram similaridade para rendimento de carcaça fria e para a composição regional de carcaças de borregos Ile de France e Hampshire Down.

O rendimento médio de carcaça fria, observado $(41,94 \%)$, foi bem menor do que o encontrado por Garcia et al. (2003a), que citaram média de $51,12 \%$ para cordeiros Suffolk criados com acesso a creep feeding ou por Alves et al. (2003), que encontraram média de $47,55 \%$ para cordeiros Santa Inês confinados. O menor valor encontrado no presente trabalho pode ser explicado pela dieta utilizada, onde os animais receberam como volumoso cana-de-açúcar in natura, enquanto nos 
outros dois experimentos foram utilizados fenos de alfafa ou de tifton. Isto se deve basicamente à baixa digestibilidade que a cana-de-açúcar apresenta, e consequentemente baixa taxa de passagem (MAGALHÃES et al., 2006), pois mesmo os animais tendo passado por jejum, o rúmen e o retículo apresentavam-se cheios no abate.

Rendimentos de carcaça fria um pouco menores do que os encontrados neste trabalho foram reportados por Almeida et al. (2006) para cordeiros Ideal e mestiços Border Leicester com Ideal. Os autores citaram médias que variaram de 38,78 a $42,40 \%$ para os cordeiros terminados em pastagem.
As perdas por resfriamento são próximas às observadas por Mendonça et al. (2003), que citaram valores de 3,77 e 5,94\%, respectivamente, para carcaças de borregos Ideal e Corriedale, abatidos com um ano de idade. Os autores comentaram que diferenças nas perdas no resfriamento podem ser influenciadas pelo genótipo dos animais, e principalmente pela distribuição da gordura de cobertura. No presente trabalho os três grupos genéticos apresentaram espessura de gordura de cobertura similares (Tabela 2). ALVES et al. (2003) encontraram valores menores, que situam-se entre 1,59 e 2,26\%, para cordeiros Santa Inês confinados recebendo diferentes níveis de energia na dieta.

Tabela 2. Características morfológicas das carcaças de cordeiros de três grupos genéticos.

\begin{tabular}{lccccc}
\hline \multirow{2}{*}{ Variáveis } & \multicolumn{3}{c}{ Grupos genéticos $^{1}$} & \multirow{2}{*}{ CV (\%) } & \multirow{2}{*}{ Prob. > F } \\
\cline { 2 - 4 } & T x HD & T x IF & T x S & & \\
\hline Comprimento carcaça, cm & 63,84 & 62,17 & 65,00 & 4,67 & 0,3111 \\
Compacidade carcaça, kg/cm & 0,27 & 0,27 & 0,27 & 7,84 & 0,9487 \\
Profundidade tórax, cm & 25,83 & 24,33 & 25,20 & 6,97 & 0,3577 \\
Comprimento pernil, cm & 34,33 & 33,50 & 35,00 & 6,93 & 0,5874 \\
Largura pernil, cm & 12,33 & 11,83 & 12,40 & 7,40 & 0,5227 \\
Profundidade pernil, cm & 17,67 & 17,50 & 18,40 & 7,35 & 0,5086 \\
Compacidade pernil, kg/cm & 0,09 & 0,09 & 0,09 & 8,91 & 0,8645 \\
Comprimento braço, cm & 18,17 & 17,33 & 18,80 & 7,65 & 0,2464 \\
Perímetro braço, cm & 14,67 & 15,08 & 15,50 & 12,30 & 0,7258 \\
Espessura gordura, mm & 2,33 & 2,33 & 2,10 & 37,07 & 0,8737 \\
\hline
\end{tabular}

${ }^{1} \mathrm{~T}$ x HD = 1/2 Texel $-1 / 2$ Hampshire Down; T x IF = 1/2Texel - 1/2Ile de France; T x S = 1/2Texel - 1/2Suffolk.

As percentagens médias de paleta, pernil e costela são próximas das observadas por Garcia et al. (2003b) para cordeiros Suffolk e, das observadas por Carvalho et al. (2007) para cordeiros Texel, porém, estes autores observaram valores maiores para pescoço do que no presente trabalho $(8,64 \%$ e $8,31 \%$ vs $6,65 \%$ ). Por outro lado, as percentagens de pernil e paleta foram maiores, e as de costela e pescoço menores, do que as observadas por Alves et al. (2003) em cordeiros Santa Inês. A composição regional das carcaças foi parecida com a observada por Almeida et al. (2006) para cordeiros mestiços Border Leicester. De acordo com Muller (1980) e Osório e Osório (2005) o pernil é um corte de primeira categoria, ou seja, de maior valor econômico, portanto é importante que os animais apresentem uma boa percentagem deste corte na carcaça.

Os três grupos genéticos não diferiram $(\mathrm{P}>0,05)$ quanto às características morfológicas (Tabela 2), confirmando a similaridade de desempenho entre eles. Estes resultados concordam com Ribeiro et al. (2001) que observaram não haver diferenças nas características morfológicas de borregos Ile de France e Hampshire Down. 
O estudo da compacidade nos permite ter uma idéia da musculosidade da carcaça ou de um corte em particular. Os valores observados para compacidade de carcaça $(0,27)$ foram menores do que os citados $(0,29)$ por Ribeiro et al. (2001), porém, foram melhores do que os encontrados $(0,24$ e 0,26$)$ por Mendonça et al. (2003) para borregos de raças produtoras de lã (Ideal) ou duplo propósito (Corriedale). No presente trabalho e no de Ribeiro et al. (2001) as raças envolvidas foram selecionadas para corte, ou seja, para maior deposição de músculos na carcaça.

De acordo com Luchiari Filho (2000) a espessura de gordura de cobertura é utilizada como medida de acabamento externo, e que sua quantidade mínima é variável geograficamente. Porém do ponto de vista qualitativo, um mínimo de 2 a 3 milímetros é necessário. A gordura protege a carcaça do encurtamento celular pelo frio durante a estocagem, porém, quando em excesso é indesejável, pois diminui o rendimento da porção comestível e implica em desperdícios. Silva Sobrinho (2001) citou que carcaças ovinas com espessura de gordura entre 2 e $5 \mathrm{~mm}$ podem ser classificadas como de gordura mediana.

Cabe salientar que se devem ter cautelas nas comparações entre as médias das características morfológicas observadas no presente trabalho com a literatura disponível, pois além dos diferentes sistemas de criação envolvidos, das diferenças genéticas, o tamanho corporal, ou peso ao abate, tem influência preponderante sobre estas características.

No presente trabalho optou-se por avaliar a composição tecidual apenas no pescoço, pois segundo Piola Júnior (2007) a composição do pescoço é muito parecida com a composição total da carcaça, apresentando correlações altas e significativas com a mesma. O autor cita valores de correlação entre percentagem de músculo na carcaça e no pescoço, percentagem de gordura na carcaça e no pescoço, e percentagem de osso na carcaça e no pescoço, respectivamente, de 0,$73 ; 0,78$ e 0,88 . Na Tabela 3 pode-se observar que não houve diferenças $(\mathrm{P}<0,05)$ entre os grupos genéticos. Estes resultados concordam com os encontrados por Kempster et al. (1987), que não observaram diferenças para percentagens de gordura e músculos nas carcaças de cordeiros mestiços Hampshire Down, Ile de France e Suffolk. Cabe salientar que estes autores compararam as carcaças dos vários grupos genéticos para uma mesma espessura de gordura de cobertura. Ribeiro et al. (2001), também, não observaram diferenças nas percentagens de osso e gordura na paleta de borregos Ile de France e Hampshire Down, porém, observaram maior percentagem de músculo nos borregos Ile de France.

Tabela 3. Composição tecidual do pescoço de cordeiros de três grupos genéticos.

\begin{tabular}{lccccc}
\hline \multirow{2}{*}{ Variáveis } & \multicolumn{3}{c}{ Grupos genéticos $^{1}$} & \multirow{2}{*}{ CV (\%) } & \multirow{2}{*}{ Prob. > F } \\
\cline { 2 - 4 } & T x HD & T x IF & T x & & \\
Meio-pescoço, kg & 0,483 & 0,549 & 0,532 & 27,02 & 0,7105 \\
Osso, kg & 0,152 & 0,144 & 0,168 & 30,43 & 0,7018 \\
Músculo, kg & 0,298 & 0,343 & 0,306 & 26,59 & 0,6264 \\
Gordura, kg & 0,033 & 0,062 & 0,058 & 59,29 & 0,2456 \\
Osso, \% & 31,07 & 26,98 & 31,38 & 16,78 & 0,2790 \\
Músculo, \% & 61,91 & 62,43 & 58,14 & 8,59 & 0,3730 \\
Gordura, \% & 7,03 & 10,58 & 10,48 & 31,26 & 0,0925 \\
\hline
\end{tabular}

${ }^{1} \mathrm{~T}$ x HD = 1/2 Texel - 1/2Hampshire Down; T x IF = 1/2 Texel - 1/2Ile de France; T x S = 1/2 Texel - 1/2 Suffolk. 
Não houve diferenças $(\mathrm{P}>0,05)$ na composição química ou centesimal do músculo $L$. dorsi entre os diferentes grupos genéticos (Tabela 4). De acordo com Oliván et al. (2000) a composição química da carne é importante na determinação da qualidade da mesma como produto alimentício. Ainda segundo os autores, há muitos fatores que influem na composição nutritiva da carne, entre estes, a espécie, a raça, o estado fisiológico, o sexo, a idade e o sistema de alimentação. A carne contém em média $75 \%$ de água, 21 a $22 \%$ de proteína, 1 a $2 \%$ de gordura e 1\% de substâncias minerais (OLIVÁN et al., 2000).

Tabela 4. Composição centesimal, perdas no descongelamento, cocção e características qualitativas da carne (Longissimus dorsi) de cordeiros de três grupos genéticos.

\begin{tabular}{|c|c|c|c|c|c|}
\hline \multirow{2}{*}{ Variáveis } & \multicolumn{3}{|c|}{ Grupos genéticos $^{1}$} & \multirow{2}{*}{ CV (\%) } & \multirow{2}{*}{ Prob. $>$ F } \\
\hline & T x HD & $\mathrm{T} \times \mathrm{IF}$ & $\mathrm{T} \times \mathrm{S}$ & & \\
\hline Umidade, $\%$ & 73,33 & 73,64 & 74,15 & 2,00 & 0,7721 \\
\hline Matéria seca, \% & 26,67 & 26,36 & 25,84 & 5,60 & 0,7683 \\
\hline Matéria mineral, \% & 2,65 & 2,56 & 2,31 & 29,30 & 0,8283 \\
\hline Proteína bruta, \% & 21,23 & 20,93 & 19,76 & 9,30 & 0,5963 \\
\hline Extrato etéreo, \% & 6,86 & 6,40 & 7,15 & 18,39 & 0,6783 \\
\hline Perdas descongel., \% & 12,57 & 12,68 & 11,64 & 13,90 & 0,5710 \\
\hline Perdas cocção, \% & 36,46 & 34,90 & 35,02 & 8,55 & 0,6290 \\
\hline Maciez $^{2}$ & 6,62 & 6,70 & 6,28 & 22,83 & 0,5574 \\
\hline Sabor $^{2}$ & 6,35 & 6,17 & 6,06 & 23,08 & 0,7471 \\
\hline Suculência $^{2}$ & 5,62 & 5,62 & 5,74 & 23,91 & 0,9292 \\
\hline
\end{tabular}

${ }^{1} \mathrm{~T} x \mathrm{HD}=1 / 2$ Texel $-1 / 2$ Hampshire Down; T x IF = 1/2Texel $-1 / 2$ Ile de France; T x S = 1/2Texel $-1 / 2$ Suffolk.

${ }^{2}$ Maciez, sabor e suculência $=$ valores de 1 (carne dura, sabor desagradável e seca) a 9 (carne muito macia, saborosa e suculenta).

Não houve diferenças $(\mathrm{P}>0,05)$ para perdas no descongelamento e na cocção, nem para as outras características qualitativas da carne (Tabela 4). A perda média de peso durante a cocção $(35,46 \%)$ foi um pouco maior do que a observada por Zeola et al. (2006) para o músculo Longissimus dorsi $(33,18 \%)$ de cordeiros Morada Nova. Sendo praticamente igual a perda citada por estes autores para o músculo Biceps femoris (35,57\%).

Os três grupos genéticos apresentaram qualidade de carne semelhante $(\mathrm{P}>0,05)$, onde, segundo Muller (1980), a maciez e o sabor podem ser classificados como acima da média e a suculência como média a levemente acima da média. Estes resultados concordam com a afirmação de Siqueira (1995), que citou que a maior parte das diferenças organolépticas das carnes são devido a diferenças nos sistemas de terminação, e que o grupo genético apresenta pouca influência sobre estas características. Ribeiro et al. (2001), também, não observaram diferenças para as características qualitativas da carne de borregos Ile de France e Hampshire Down.

\section{Conclusão}

$\mathrm{Na}$ produção de carne ovina pode ser utilizado qualquer um dos grupos genéticos estudados $(1 / 2$ Texel $-1 / 2$ Hampshire Down, $1 / 2$ Texel $-1 / 2$ Ile de France e $1 / 2$ Texel - 1/2 Suffolk), pois apresentam carcaças e carnes semelhantes. 


\section{Referências}

ALMEIDA, H. S. L.; PIRES, C. C.; GALVANI, D. B.; LIMA, R. F.; HASTENPFLUG, M.; GASPERIN, B. G. Características de carcaça de cordeiros Ideal e cruzas Border Leicester X Ideal submetidos a três sistemas alimentares. Ciência Rural, Santa Maria, v. 36, n. 5, p. 1546-1552, 2006.

ALVES, K. S.; CARVALHO, F. F. R.; FERREIRA, M. A.; VERAS, A. S. C.; MEDEIROS, A. N.; NASCIMENTO, J. F.; NASCIMENTO, C. R. S.; ANJOS, A. V. A. Níveis de energia em dietas para ovinos Santa Inês: Características de carcaça e constituintes corporais. Revista Brasileira de Zootecnia, Viçosa, MG, v. 32, n. 6, p. 1927-1936, 2003. Suplemento 2.

BRIDI, A. M.; SILVA, C. A. Métodos de avaliação da carcaça e da carne suina. Londrina: Midiograf, 2007. 97 p.

BRISOLA, M. V.; SANTO, E. E. Panorama da cadeia produtiva da ovinocultura no Brasil. In: SIMPÓSIO MINEIRO DE OVINOCULTURA, 3., Lavras, 2003. Anais... Lavras: UFLA, 2003. p. 11-24.

CARDELLINO, R. A. Sistemas de produção de carne ovina utilizando cruzamentos. In: SIMPÓSIO PAULISTA DE OVINOCUlTURA, 1., 1989, Botucatu. Anais... Campinas: Fundação Cargill, 1989. p. 97-104.

CARVALHO, S.; BROCHIER, M. A.; PIVATO, J.; TEIXEIRA, R. C.; KIELING, R. Ganho de peso, características da carcaça e componentes não-carcaça de cordeiros da raça Texel terminados em diferentes sistemas alimentares. Ciência Rural, Santa Maria, v. 37, n. 3, p. 821-827, 2007.

GARCIA, C. A.; COSTA, C.; MONTEIRO, A. L. G.; NERES, M. A.; ROSA, G. J. M. Níveis de energia no desempenho e características da carcaça de cordeiros alimentados em creep feeding. Revista Brasileira de Zootecnia, Viçosa, MG, v. 32, n. 6, p. 1371-1379, 2003 a.

Medidas objetivas e composição tecidual da carcaça de cordeiros alimentados com diferentes níveis de energia em creep feeding. Revista Brasileira de Zootecnia, Viçosa, MG, v. 32, n. 6, p. 1380-1390, 2003 b.

GARCIA, I. F. F.; PEREIRA, I. G. Manejo de cruzamentos na ovinocultura. In: SIMPÓSIO MINEIRO DE OVINOCULTURA, 3., 2003, Lavras. Anais... Lavras: UFLA, 2003. p. 49-79.

KEMPSTER, A. J.; CROSTON, D.; GUY, D. R.; JONES, D. W. Growth and carcass characteristics of crossbred lambs by ten sire breeds, compared at the same estimated carcass subcutaneous fat proportion. Animal Production, Cambridge, v. 44, n. 1, p. 83-98, 1987.

LUCHIARI FILHO, A. Pecuária da carne bovina. São Paulo: A. Luchiari Filho, 2000. 134 p.
MAGALHÃES, A. L. R.; CAMPOS, J. M. S.; CABRAL, L. S.; MELLO, R.; FREITAS, J. A.; TORRES, R. A.; VALADARES FILHO, S. C.; ASSIS, A. J. Cana-deaçúcar em substituição à silagem de milho em dietas para vacas em lactação: parâmetros digestivos e ruminais. Revista Brasileira de Zootecnia, Viçosa, MG, v. 35, n. 2, p. 591-599, 2006.

MENDONÇA, G.; OSÓRIO, J. C.; OLIVEIRA, N. M.; OSÓRIO, M. T.; ESTEVES, R.; WIENGARD, M. M. Morfologia, características da caraça e componentes do peso vivo em borregos Corriedale e Ideal. Ciência Rural, Santa Maria, v. 33, n. 2, p. 351-355, 2003.

MULLER,L. Normas para a avaliação de carcaças e concursos de carcaças de novilhos. Santa Maria: UFSM, 1980. 31 p.

OLIVÁN, M.; MOCHA, M.; MARTINEZ, M.. J.; GARCIA, M. J.; NOVAL, G.; OSORO, K. Análisis químico de la carne. In: CAÑEQUE, V.; SAÑUDO, C. (Ed.). Metodologia para el estúdio de la calidad de la canal y de la carne em rumiantes. Madrid: INIA, 2000. p. 181-203.

OSÓRIO, J. C. S.; OSÓRIO, M. T. M. Produção de carne ovina: Técnicas de avaliação "in vivo" e na carcaça. 2. ed. Pelotas: Ed. Universitária, UFPEL, 2005. 82 p.

OSÓRIO, J. C. S.; OSÓRIO, M. T. M.; JARDIM, P. O. C.; PIMENTEL, M.; POUEY, J. L.; LUDER, W. E.; CARDELINO, R. A.; OLIVEIRA, N. M.; BORBA, M. F.; MOTTA, L.; ESTEVES, R. Métodos para avaliação da produção da carne ovina: in vivo, na carcaça e na carne. Pelotas: Universidade Federal de Pelotas, 1998. $107 \mathrm{p}$.

PIOLA JÚNIOR, W. Desempenho e características de carcaça de cordeiros submetidos a diferentes niveis de energia. Londrina: Universidade Estadual de Londrina, 2007.Dissertação (Mestrado em Ciência Animal) Departamento de Medicina Veterinária Preventiva. Universidade Estadual de Londrina, Londrina.

RIBEIRO, E .L. A.; ROCHA, M. A.; MIZUBUTI, I. Y.; SILVA, L. D. F.; RIBEIRO, H. J. S. S.; MORI, R. M. Carcaça de borregos Ile de France inteiros ou castrados e Hampshire Down castrados abatidos aos doze meses de idade. Ciência Rural, Santa Maria, v. 31, n. 3, p. 479482, 2001.

SAS INSTITUTE. SAS/STAT User's Guide. Cary: SAS Institute Inc., 1994.

SILVA SOBRINHO, A. G. Criação de ovinos. Jaboticabal: FUNEP, 2001. 302 p.

SILVA, D. J.; QUEIROZ, C. Análise de alimentos: métodos químicos ebiológicos. Viçosa, MG: Universidade Federal de Viçosa, 2002. 235 p. 
SIQUEIRA, E. R. Carne de cordeiro: é preciso evoluir. São Manoel: ASPACO, 1995. p. 6. (O avelheiro, n. 37).

Raças e sistemas de produção. In: PRODUÇÃO

DE OVINOS, 1., 1990, Jaboticabal. Anais... Jaboticabal: FUNEP, 1990. p. 1-25.

Recria e terminação de cordeiros em confinamento. In: NUTRIÇÃO OVINOS, 1., 1996, Jaboticabal. Anais... Jaboticabal: FUNEP, 1996. p. 175-212.
ZEOLA, N. M. B. L.; SOUZA, P. A.; SILVA SOBRINHO, A. G.; PELICANO, E. R. L. Parâmetros de qualidade da carne de cordeiros submetida aos processos de maturação e injeção de cloreto de cálcio. Ciência Rural, Santa Maria, v. 36, n. 5, p. 1558-1564, 2006. 
